\title{
PENCIPTAAN TOKOH GENDUT DALAM NASKAH TERDAMPAR KARYA SLAWOMIR MROZEK TERJEMAHAN \\ A. KASIM AHMAD
}

Skripsi

untuk memenuhi salah satu syarat mencapai derajat Sarjana S-1

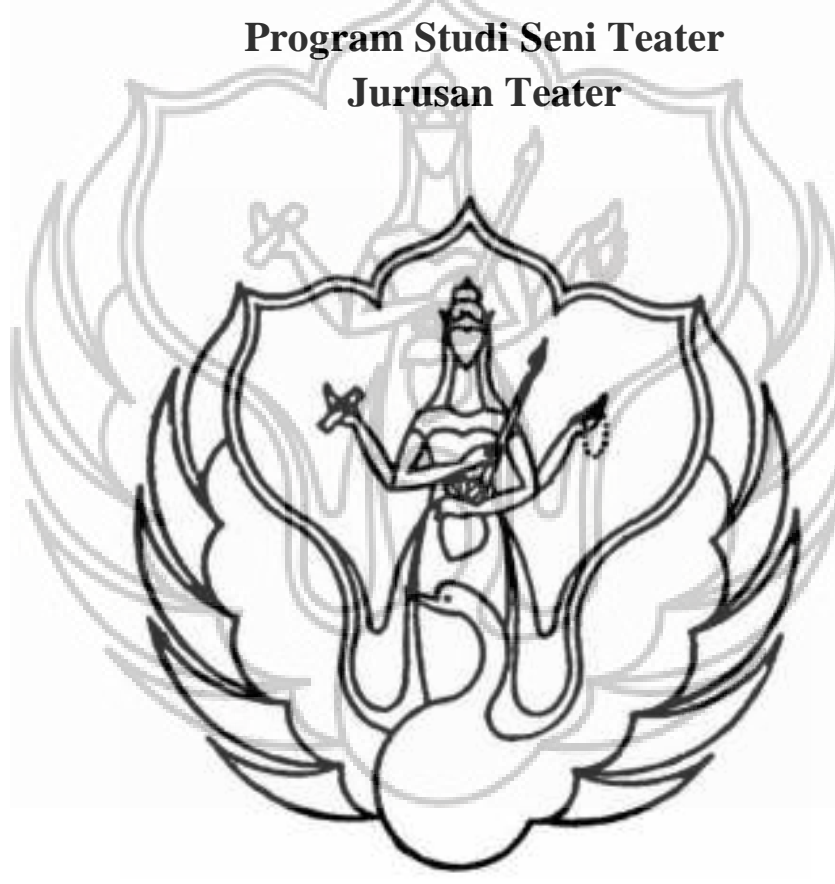

oleh

Tiara Arianggi

NIM. 1110654015

FAKULTAS SENI PERTUNJUKAN INSTITUT SENI INDONESIA YOGYAKARTA 2016 


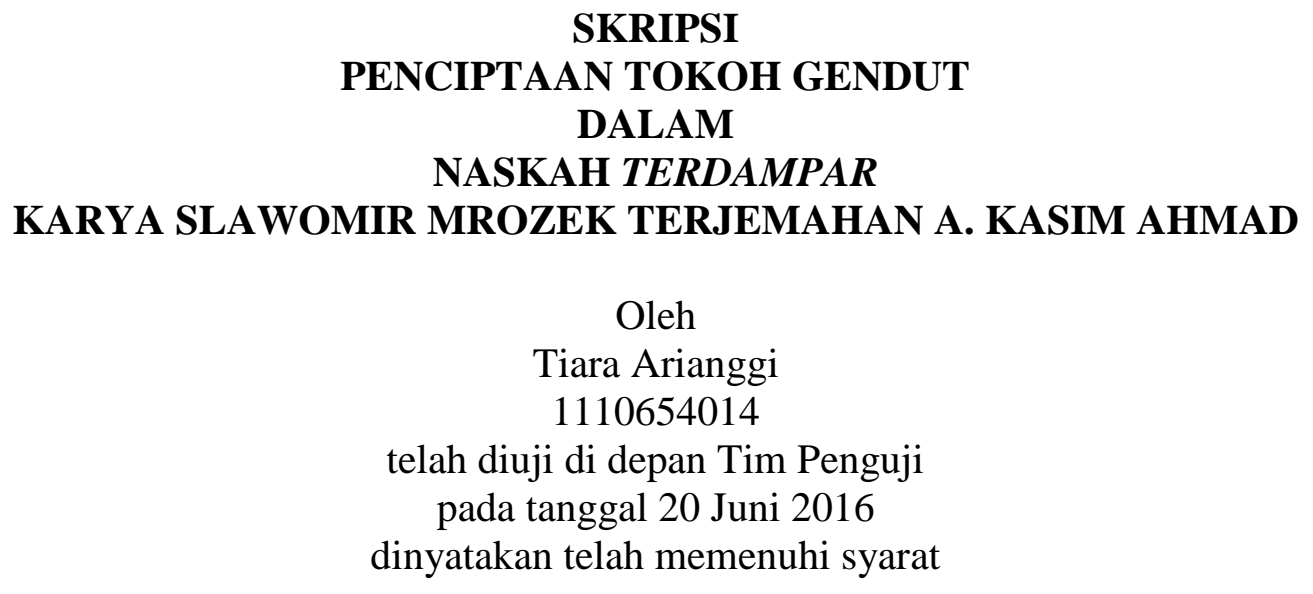

Susunan Tim Penguji

Ketua Tim Penguji/Penguji Ahli Pembimbing I

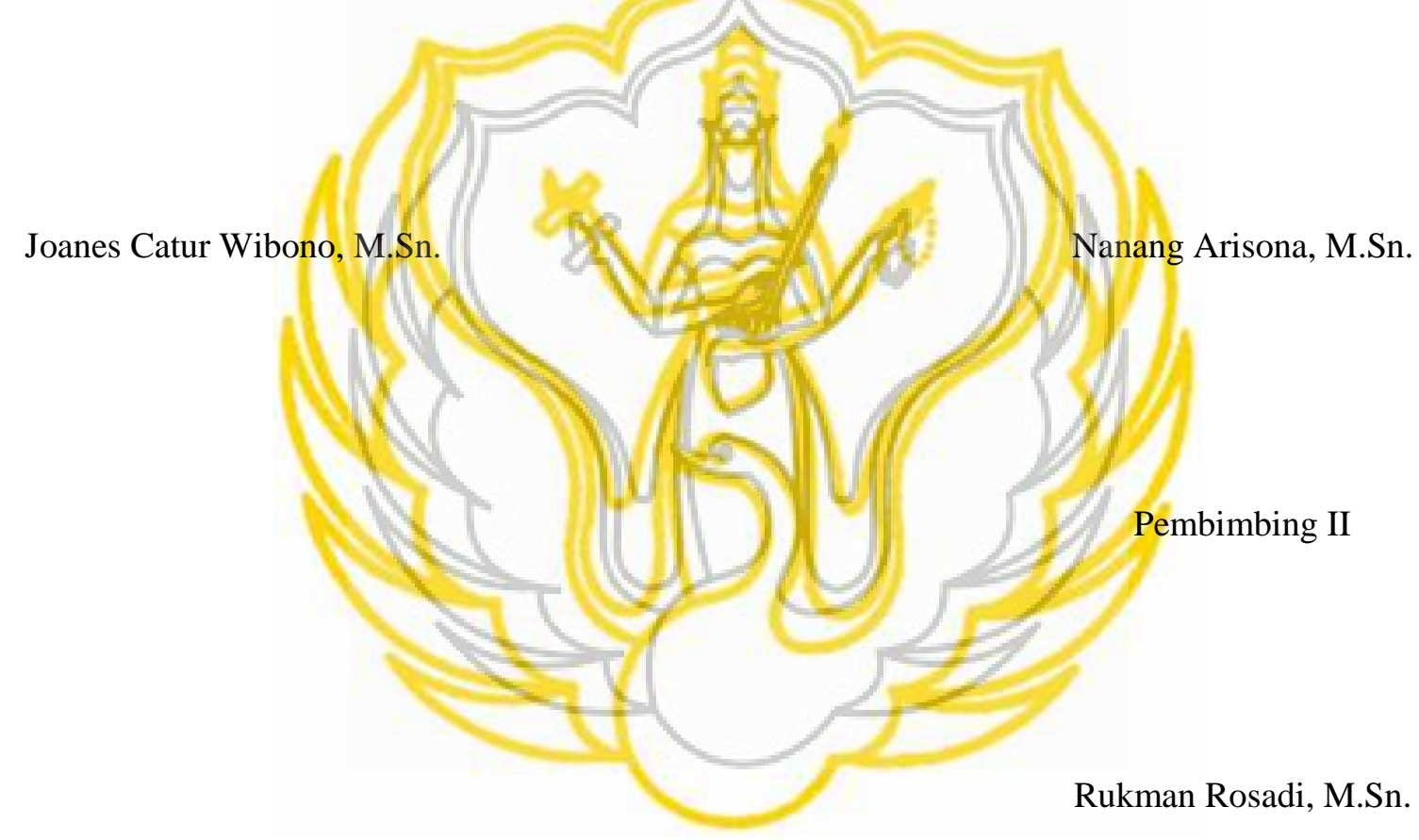

Yogyakarta,

Mengetahui

Dekan Fakultas Seni Pertunjukan

Prof. Dr. Hj. Yudiaryani, M.A.

NIP.195606301987032001 


\section{MOTTO}

"Perjuangan mengajari banyak hal tentang bagaimana cara untuk bertahan hidup"

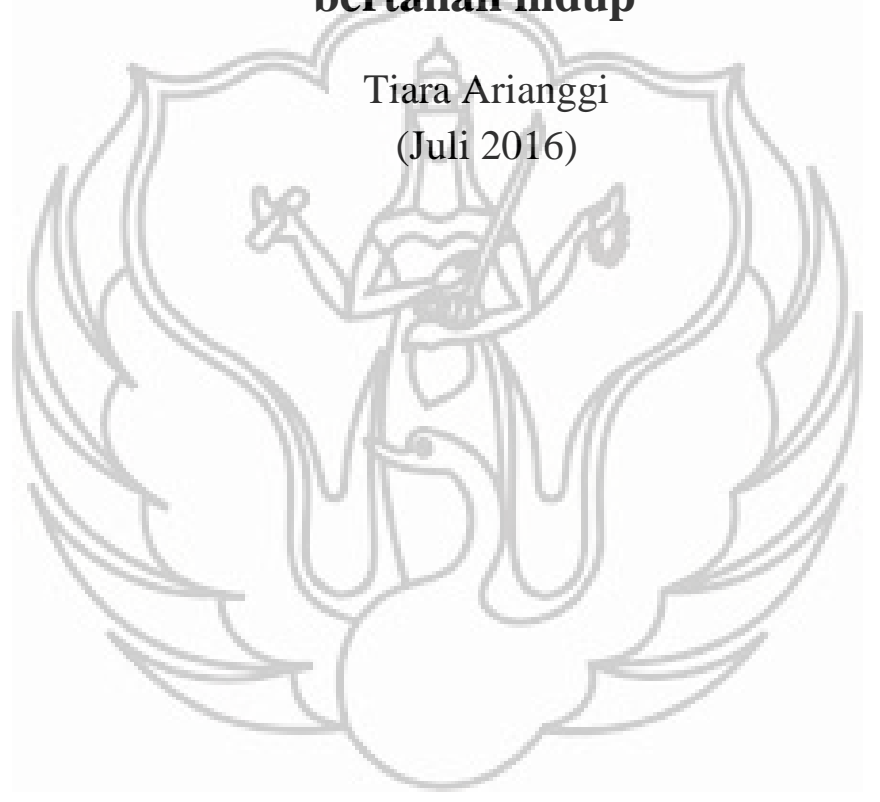

\section{UPT Perpustakaan ISI Yogyakarta}




\section{SURAT PERNYATAAN}

Dengan ini saya menyatakan dalam skripsi ini tidak terdapat karya yang pernah diajukan untuk memperoleh gelar sarjana di perguruan tinggi, dan sepanjang pengetahuan saya tidak terdapat karya atau pendapat yang pernah ditulis oleh orang lain kecuali yang secara tertulis diakui dalam skripsi ini dan disebut di kepustakaan. Apabila pernyataan saya ini tidak benar, saya sanggup dicabut hak dan gelar saya sebagai Sarjana Seni dari Program Studi Teater Jurusan Teater Fakultas Seni Pertunjukkan Institut Seni Indonesia Yogyakarta.

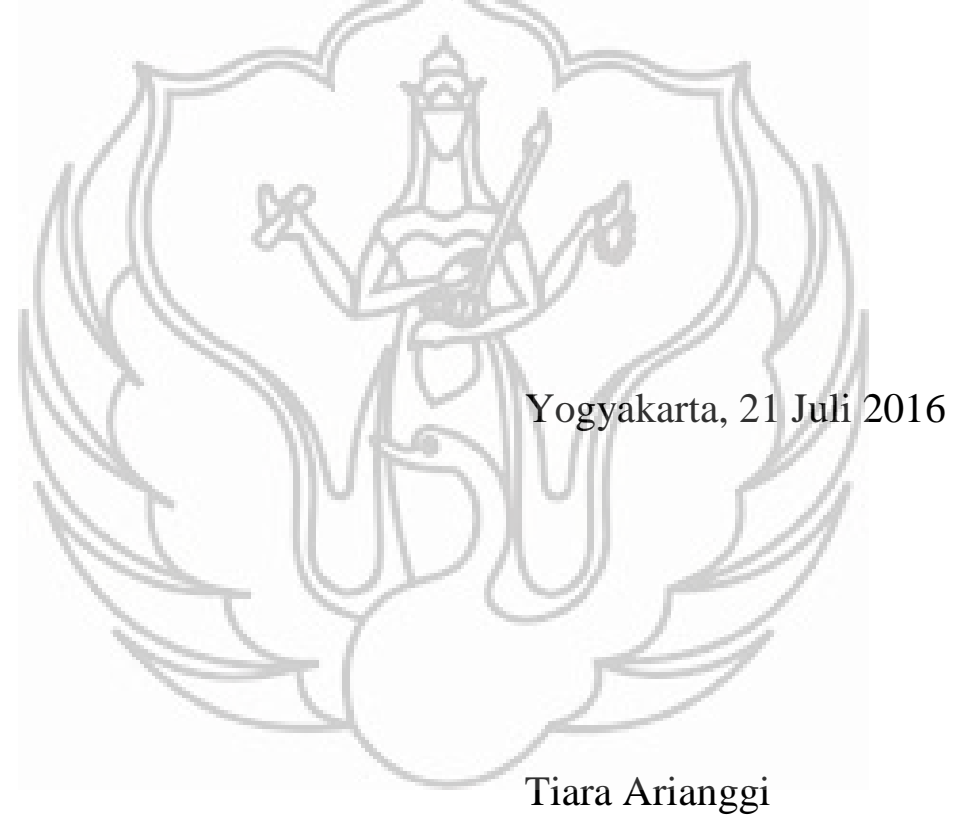

\section{UPT Perpustakaan ISI Yogyakarta}




\section{KATA PENGANTAR}

Bismillahhirohmannirohim. Sepatah kata pun rasanya tidak dapat mewakili bagaimana caranya mengucap rasa syukur atas apa yang sudah Engkau berikan, Engkau limpahkan dan Engkau anugerahkan. Alhamdulillahhirobil'alamin, telah sampailah pada titik dimana saya sampai untuk mencapai selangkah demi selangkah kehidupan, rintangan demi rintangan yang mulai terselesaikan.

Sulit sekali untuk diungkapkan, bagaimana rasa hati dan fikiran yang saling jalan beriringan melewati gejolak-gejolak/selama waktu yang tidak singkat ini menjalani proses penciptaan demi menyelesaikan ujian Tugas Akhir Kompetensi keaktoran di Jurusan Teater FSP ISI Yogyakarta. Segala bentuk upaya, keringat, pengorbanan dan tenaga bukan lah suatu hal yang mudah untuk dilalui. Maka saya sebagai manusia biasa ini tidak akan pernah bisa bertahan dengan penuh keyakinan dan kekuatan jika tidak diiringi oleh ikhtiar dan berdoa. Lagi - lagi ucapan rasa syukur yang saya tuturkan pada Allah SWT dari segala hal yang tidak bisa saya sebutkan satu persatu dan karena Dialah saya di pertemukan oleh begitu banyak perantara kebaikan yang saya terima dalam kehidupan yang saya jalani.

Seiiring berjalannya waktu dalam menghadapi kenyataan yang cukup berat bagi saya, namun semua ini dapat terselesaikan tentu atas bantuan berbagai pihak, untuk itu adapun rasa hormat dan terimakasih saya ucapkankan kepada :

\section{UPT Perpustakaan ISI Yogyakarta}


1. Nenek Perempuan Siti Cholillah dan Alm. Nenek Laki Sulbasrin Ali BBA yang sedari kecil saya selalu dalam bimbingan, kesabaran dalam membesarkan saya dengan kehangatan kasih sayang, rasa support yang selalu hadir dalam setiap segala aktivitas positif, pembelaan dalam setiap keluh kesah dalam menghadapi segala rintangan, saran, pesan, serta nasihat yang tertera dalam setiap kalimat - kalimat yang dituturkan, sehingga dapat membuat diri ini selalu teguh dan tidak merasa sepi sendiri. Nenenk perempuan, nenek aki kelulusan ini ku persembahkan untuk kalian. Terimakasih yang begitu mendalam telah sangat mendukung pendidikan Tiara dari TK bahkan sampai Sarjana. Nek aki yang sudah tiada di muka bumi ini, tetapi harapan kebahagiaan selalu ada untuk mu. Nek perempuan yang sudah lanjut usia, adalah satu-satunya nenek yang ku miliki saat ini, pelukan, ciuman bahkan rasa terimakasih pun tidak akan pernah cukup untuk dapat membalas kasih sayang yang diberikan pada Tiara. Harapan tiara untuk nenek bahagia selalu dunia dan akhirat. Amin. I'm really love you Grandma, Grandpa.

2. Orang tua Bapak Iwan Heriawan dan Ibu Lila Arianita yang juga selalu memebarikan kasih sayang, dukungan, kesabaran dalam menahadapi segala persoalan dalam diri baik scara moral maupun material.

3. Kepada Rektor Institut Seni Indonesia Yogyakarta.

4. Kepada Dekan Fakultas Seni Pertunjukkan Institut Seni Indonesia Yogyakarta.

\section{UPT Perpustakaan ISI Yogyakarta}


5. Bapak Joanes Catur Wibono, M.Sn selaku Ketua Jurusan Teater sekaligus juga sebagai penguji yang telah memberi semangat, kritik serta saran demi terselesaikannya studi dalam hal karya tulis maupun karya pentas.

6. Bapak Nanang Arisona, M.Sn selaku pembimbing I yang telah sabar menghadapi saya selaku mahasiswa Tugas Akhir dan khususnya dalam berhadapan langsung dengan karya tulis yang wajib untuk diselesaikan secara baik dan benar. Terimakasih bapak atas segala saran, pencerahan, masukan dan segala macam bentuk kehadiran bapak demi membantu terselesaikanya Tugas Akhir ini.

7. Bapak Rukman Rosadi, M.Sn selaku dosen pembimbing II yang juga begitu sabar menghadapi penulis dalam memberikan masukan, saran, pembelajaran keaktoran, perfilman, pengalaman dalam dunia akting, ilmu pengetahuan teori maupun praktek dalam dunia keaktoran, perkembangan penciptaan tokoh demi tokoh yang harus di lalui hingga akhirnya dapat terselesaikan dengan baik.

8. Kepada seluruh dosen pengajar Jurusan Teater yang terkait. Terimakasih atas ketersediaanya selalu untuk membimbing dalam proses pembelajaran selama bertahun-tahun, tanpa ada keluh kesah, dan penuh rasa sabar demi keberhasilan mahasiswanya.

9. Seluruh staf yang ada di perpustakaan Institut Seni Indonesia Yogyakarta. Selalu memberikan kemudahan dan juga refrensi-refrensi dalam proses

\section{UPT Perpustakaan ISI Yogyakarta}


pembelajaran dan juga pembuatan skripsi ini sebagai salah satu syarat kelulusan di perguruan tinggi sebagai S1 Sarjana Seni.

10. Seluruh staf pengajar dan karyawan Jurusan Teater, karyawan/karyawati Fakultas Seni Pertunjukkan dan rektorat Institut Seni Indonesia Yogyakarta, terimaksih atas pelayanan yang baik terhadap seluruh kebutuhan dalam menjalani kelancaran sistem perkuliahan.

11. Adik - adik kecil Ratih Arianggi dan Biancha Arianggi, yang selalu memberikan semangat dan dalam menuai rasa rindu terhadap adik - adik seperti menemukan semngat baru dalam citaku.

12. Bi Elin Arianita dan Om Erry Sukmawijaya, yang selalu mendukung atas terselenggaranya pementasan dalam mata kuliah yang di wajibkan dalam memenuhi syarat standar kelulusan. Selalu memeberikan wejangan terhadap hal - hal yang menyangkut diri dalam meraih masa depan. Terimakasih yang mendalam untuk segala dukungan dan terutama kesabaran dalam menghadapi tingkah laku ku yang tidak luput dari salah. Selama. Bi elin, Om wiwit terimaksih, selama 5 tahun ini telah mendampingi Tiara dengan begitu penuh kasih dan sayang. Mendukung penuh atas pendidikan dan kemajuan Tiara dalam berkarier. Tidak ada hal lain yang bisa diucapkan selain kata Terimaksih. Semoga Allah selalu memberikan rahmat, kesehatan dan rezeky yang berlimpah. Amin.

\section{UPT Perpustakaan ISI Yogyakarta}


13. Seluruh pendukung proses "Terdampar" dan semua yang pernah mendukung karya ujian penulis, mulai dari ujian mata kuliah tehnik peran I hingga ujian Tugas Akhir.

14. Seluruh team produksi pertunjukkan yang pernah dilalui selama beberapa semester dalam memenuhi syarat kelulusan perkuliahan yang telah ikhlas meluangkan waktu, tenaga, pikiran sehingga karya - karya pertunjukkan dapat terselesaikan dengan baik.

15. Teman - teman mahasiswa Jurusan Teater yang juga selalu ikut andil dalam mendukung terselenggaranya karya - karya pementasan hingga selesai masa studi untuk menempuh derajat strata 1.

16. Teman - teman mahasiswa Jurusan Teater angkatan 2011, Barisan Anak Teater (BARATA), yang juga selalu ikut andil dalam menggarap suatu pertunjukkan, baik dalam pembuatan karya diluar maupun saat - saat menjalani ujian mata kuliah selama masa perkuliahan. Sealalu kompak, bershaja dan saling mendukung. Teman - teman angkatan 2011, lovely group.

17. Kerabat Tugas Akhir (TA), Banyu Bening dan Firman Ichlasul Amal yang selalu berdebat dalam diskusi demi diskusi dalam konteks penghafalan naskah, memahami maksud dan tujuan isi naskah sehingga memancing keributan dan pembenturan kelompok dengan saling memegang kebernarannya masing - masing. Tetapi dengan begitu dapat disimpulkan bahwasanya tidak ada permasalahan, tetapi menguatkan rajutan dalam

\section{UPT Perpustakaan ISI Yogyakarta}


kelompok, terjalin komunikasi dan satu tujuan yang baik dalam menggarpap pertunjukkan naskah "Terdampar" ini. Hingga beberapa waktu ingin pentas, rasa haru saat bersama mulai terasa, rasa saling mendukung, memberikan energi positif serta rasa sabar dari masing masing personal.

18. Sutradara “Terdampar” Lita Pauh Indrajaya yang selalu sabar menemani, mendukung, memeberikan masukan - masukan, saran, nasihat juga kesabaran menghadapi penulis dalam menciptakan karakter yang akan di mainkan. Selain itu berkat bantuan kakak, maka pertunjukkan pun berjalan dengan baik.

19. Seorang yang selalu membuat gaduh dalam fikiran dan hati karena kalau marah suka bentak - bentak tapi kadang menenangkan, yaitu Muhammad Banyu Bening. Kerabat terdekat pada saat - saat TA, orang yang selalu ada dalam masa - masa sulit, bimbang, sedih, gundah gulana dalam mengahadapi Tugas Akhir.

20. Karyawan - karyawan, Bapak Erry Sukmawijaya dan Elin Arianita selaku Pemilik perusahan rumah makan Nasi Goreng Mas Wit (NASGOMI), Warung Presto Alamanda (WPA), yang tidak jarang memberikan spornsor - sponsor baik fresh money atau pun berupa makanan berat demi kelancaran terselenggaranya sebuah karya pementasan teater dalam rangka ujian mata kuliah.

21. Seluruh rekan - rekan yang tidak dapat penulis sebutkan satu persatu.

\section{UPT Perpustakaan ISI Yogyakarta}


Penulis menyadari bahwa tulisan ini masih jauh dari kesempurnaan.Maka, sudilah kiranya pembaca yang budiman dapat memberi tegur sapa, saran kritik, serta masukan yang membangun bagi penulisan selanjutnya. Semoga laporan pertanggungjawaban tugas akhir ini dapat memberikan sumbangsih dalam dunia keilmuan khususnya Teater.

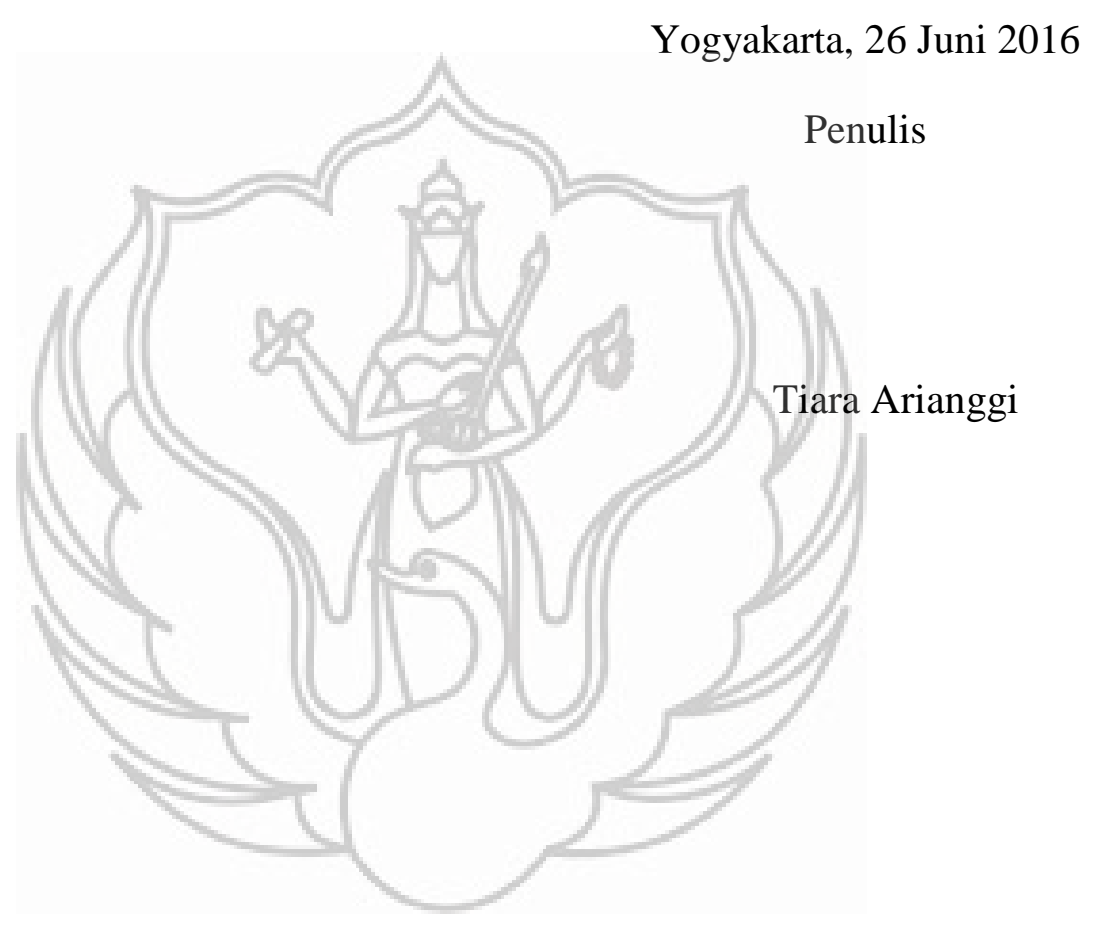




\section{DAFTAR ISI}

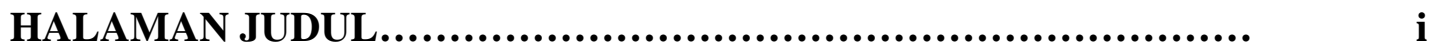

HALAMAN PENGESAHAN............................................ ii

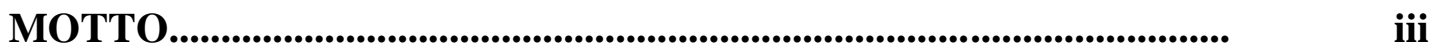

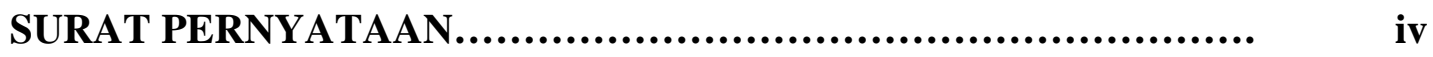

KATA PENGANTAR................................................. v

DAFTAR ISI......................................................... xii

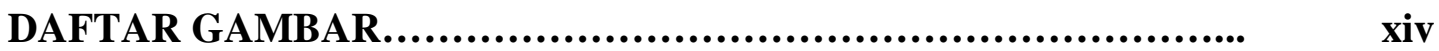

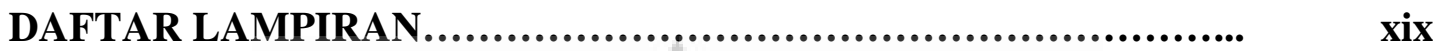

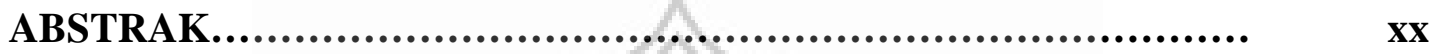

\section{BAB I PENDAHULUAN}

A. Latar Belakang...................................................

B. Rumusan Penciptaan................................................ 4

C. Tujuan Penciptaan.................................................. 4

D. Tinjauan Karya ............................................... 4

E. Landasan Teori...................................................... 5

F. Metode Memerankan Tokoh........................................ 9

1. Analisis naskah............................................ 10

2. Menentukan lawan main....................................... 10

3. Latihan tangga nada......................................... 10

4. Pencarian refrensi film atau dokumentasi pertunjukkan............ 11

5. Observasi tokoh............................................ 12

6. Penciptaan karakter tokoh.................................. 12

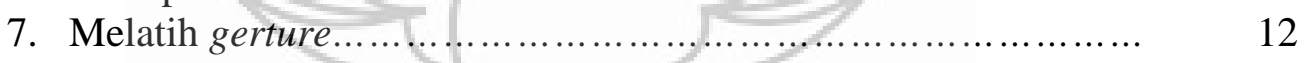

G. Sistematika Penulisan......................................... 13

\section{BAB II ANALISIS KARAKTER}

A. Ringkasan Cerita............................................... 15

B. Analisis Struktur dan Tekstur Naskah "Terdampar".................. 18

1. Analisis Struktur............................................... 18

a. Tema...................................................... 19

b. Alur..................................................... 20

c. Penokohan (Karakter) ................................... 26

2. Analisis Tekstur............................................... 37

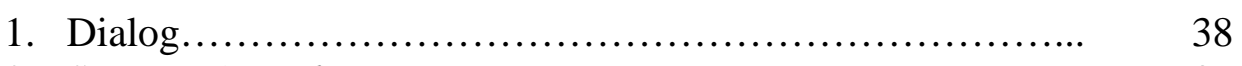

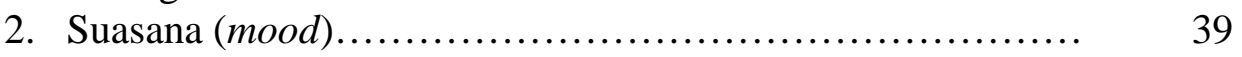

3. Spektakel.......................................... 46

\section{UPT Perpustakaan ISI Yogyakarta}


C. Analisis Bentuk Lakon.......................................... 48

D. Analisis Gaya Lakon............................................... 49

\section{BAB III PROSES PENCIPTAAN PEMERANAN}

A. Konsep Pemeranan............................................. 51

B. Proses Training .................................................. 52

1. Latihan Vokal Menyayi.................................... 52

a. Latihan Pernafasan...................................... 53

b. Latihan Tangga Nada................................... 54

c. Latihan Teknik Bernyayi.................................... 55

d. Latihan Dialek dan Warna Vokal............................... 57

2. Olah Tubuh.................................................. 59

a. Pemanasan Tubuh.............................................. 60

b. Irama Tubuh dan Dialog.................................... 60

c. Eksplorasi Tubuh............................................. 61

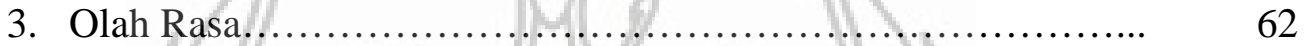

4. Observasi................................................ 64

5. Menciptakan Karakter Tokoh................................... 67

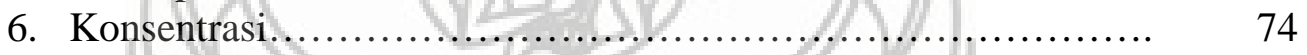

7. Berlatih Alienasi ............................................. 75

8. Olah Fikir dan Improvisasi.................................. 78

9. Merubah Fisik................................................... 81

C. Pertunjukkan Utuh................................................. 82

D. Proses Penciptaan Pemeranan dalam Pementasan ..................... 84

1. Pemilihan Naskah........................................... 85

2. Reading....................................................... 86

3. Blocking .................................................. 87

4. Runtrough ................................................. 123

5. Gladi Kotor................................................ 125

6. General Rehealsall......................................... 126

7. Pementasan.................................................. 126

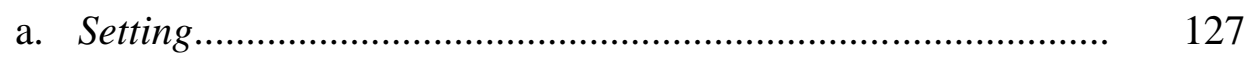

b. Lighting.................................................. 130

c. Make up..................................................... 131

d. Costume....................................................... 135

BAB 1V KESIMPULAN dan SARAN

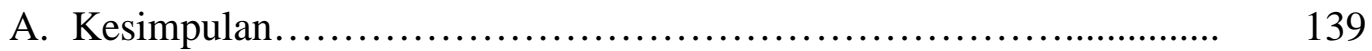

B. Saran ............................................................... 141

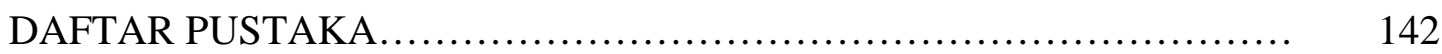

LAMPIRAN ....................................................... 143

\section{UPT Perpustakaan ISI Yogyakarta}




\section{DAFTAR GAMBAR}

Gambar No. 1 Blocking fix menuju pentas......................... 91

Gambar No. 2 Blocking fix menuju pentas........................ 91

Gambar No. 3 Blocking fix menuju pentas......................... 92

Gambar No. 4 Blocking fix menuju pentas........................ 92

Gambar No. 5 Blocking fix menuju pentas........................ 93

Gambar No. 6 Blocking fix menuju pentas......................... 93

Gambar No.7 Blocking fix menuju pentas......................... 94

Gambar No. 8 Blocking fix menuju pentas........................ 95

Gambar No. 9 Blocking fix menuju pentas........................ 95

Gambar No. 10 Blocking fix menuju pentas.......................... 96

Gambar No. 11 Blocking fix menuju pentas......................... 96

Gambar No. 12 Blocking fix menuju pentas.......................... 97

Gambar No. 13 Blocking fix menuju pentas.......................... 98

Gambar No. 14 Blocking fix menuju pentas.......................... 98

Gambar No. 15 Blocking fix menuju pentas........................ 99

Gambar No. 16 Blocking fix menuju pentas......................... 99

Gambar No. 17 Blocking fix menuju pentas......................... 100

Gambar No. 18 Blocking fix menuju pentas........................ 101

Gambar No. 19 Blocking fix menuju pentas......................... 101

Gambar No. 20 Blocking fix menuju pentas......................... 102

Gambar No. 21 Blocking fix menuju pentas........................ 102 
Gambar No. 22 Blocking fix menuju pentas............................ 103

Gambar No. 23 Blocking fix menuju pentas........................... 103

Gambar No. 24 Blocking fix menuju pentas............................. 104

Gambar No. 25 Blocking fix menuju pentas............................ 104

Gambar No. 26 Blocking fix menuju pentas............................ 105

Gambar No. 27 Blocking fix menuju pentas............................ 105

Gambar No. 28 Blocking fix menuju pentas............................ 106

Gambar No. 29 Blocking fix menuju pentas............................. 106

Gambar No. 30 Blocking fix menuju pentas............................. 107

Gambar No. 31 Blocking fix menuju pentas.............................. 107

Gambar No. 32 Blocking fix menuju pentas............................. 108

Gambar No. 33 Blocking fix menuju pentas............................ 108

Gambar No. 34 Blocking fix menuju pentas.............................. 109

Gambar No. 35 Blocking fix menuju pentas............................. 110

Gambar No. 36 Blocking fix menuju pentas............................ 110

Gambar No. 37 Blocking fix menuju pentas ............................ 111

Gambar No. 38 Blocking fix menuju pentas........................... 111

Gambar No. 39 Blocking fix menuju pentas............................ 112

Gambar No. 40 Blocking fix menuju pentas.......................... 112

Gambar No. 41 Blocking fix menuju pentas........................... 113

Gambar No. 42 Blocking fix menuju pentas.......................... 114

Gambar No. 43 Blocking fix menuju pentas............................ 115

Gambar No. 44 Blocking fix menuju pentas........................... 115 
Gambar No. 45 Blocking fix menuju pentas............................ 116

Gambar No. 46 Blocking fix menuju pentas........................... 116

Gambar No. 47 Blocking fix menuju pentas........................... 117

Gambar No. 48 Blocking fix menuju pentas........................... 117

Gambar No. 49 Blocking fix menuju pentas............................. 118

Gambar No. 50 Blocking fix menuju pentas............................. 119

Gambar No. 51 Blocking fix menuju pentas.......................... 120

Gambar No. 52 Blocking fix menuju pentas............................ 120

Gambar No. 53 Blocking fix menuju pentas............................. 121

Gambar No. 54 Blocking fix menuju pentas............................. 121

Gambar No. 55 Blocking fix menuju pentas............................. 122

Gambar No. 56 Blocking fix menuju pentas........................... 123

Gambar No. 57 Setting Pohon berbentuk otak manusia.................... 128

Gambar No. 58 Setting karang dibuat seperti mimbar..................... 129

Gambar No. 59 Setting tampak keseluruhan di atas panggung............ 129

Gambar No. 60 Proses make up menggunakan lem latek................. 132

Gambar No. 61 Proses make up dengan lem latek........................ 132

Gambar No. 62 Hasil make up akhir.............................. 133

Gambar No. 63 Pemasangan rambut palsu setelah selesai make up........ 133

Gambar No. 64 Kostum tampak depan............................... 134

Gambar No. 65 Kostum tampak samping............................ 135

Gambar No. 66 Kostum tampak belakang............................. 135

Gambar No. 67 Slawomir Mrozek..................................... 174

\section{UPT Perpustakaan ISI Yogyakarta}


Gambar No. 68 Proses latihan bernyayi pada saat latihan................ 183

Gambar No. 69 Proses latihan bernyayi bersama pemusik............... 183

Gambar No. 70 Pemusik saat latihan untuk mengiringi ilustrasi........... 184

Gambar No. 71 Latihan respon tubuh dalam bentuk melingkar............. 185

Gambar No. 72 Latihan saat olah tubuh, sembari berdialog................185

Gambar No. 73 Latihan reading di stage seluruh aktor................... 186

Gambar No. 74 Latihan reading di stage seluruh aktor.................. 187

Gambar No. 75 Konsultasi dengan dosen pembimbing para aktor......... 187

Gambar No. 76 Properti Koper................................. 188

Gambar No. 77 Properti Tempat Buah............................... 189

Gambar No. 78 Properti Vas Bunga................................. 189

Gambar No. 79 Properti Piring..................................... 190

Gambar No. 80 Properti Sendok................................. 190

Gambar No. 81 Properti Garpu................................ 191

Gambar No. 82 Properti Kartu.................................. 191

Gambar No. 83 Properti Handuk................................ 192

Gambar No. 84 Properti Bolpoint.............................. 192

Gambar No. 85 Properti Taplak................................. 193

Gambar No. 86 Foto pentas naskah Terdampar....................... 194

Gambar No. 87 Foto pentas naskah Terdampar........................ 194

Gambar No. 88 Foto pentas naskah Terdampar....................... 195

Gambar No. 89 Foto pentas naskah Terdampar....................... 195

Gambar No. 90 Foto pentas naskah Terdampar....................... 196

\section{UPT Perpustakaan ISI Yogyakarta}


Gambar No. 91 Foto pentas naskah Terdampar..................... 196

Gambar No. 92 Foto pentas naskah Terdampar..................... 197

Gambar No. 93 Foto pentas naskah Terdampar...................... 197

Gambar No. 94 Foto pentas naskah Terdampar..................... 198

Gambar No. 95 Foto pentas naskah Terdampar...................... 198

Gambar No. 96 Poster Fix........................................ 199

Gambar No. 97 Publikasi Sosial Media “Instagram”................... 200

Gambar No. 98 Publikasi Sosial Media "PATH"....................... 201

Gambar No. 99 Publikasi Sosial Media "Facebook".................... 202

Gambar No. 100 Booklet Luar................................... 203

Gambar No. 101 Booklet Dalam.................................. 203 


\section{DAFTAR LAMPIRAN}

Lampiran No. 1 Naskah Drama Terdampar............................................. 144

Lampiran No. 2 Biografi Penulis..................................... 175

Lampiran No. 3 Latihan.......................................... 182

Lampiran No. 4 Properti Tokoh Gendut............................. 188

Lampiran No. 5 Foto Pementasan........................................ 194

Lampiran No. 6 Publikasi.............................................. 199

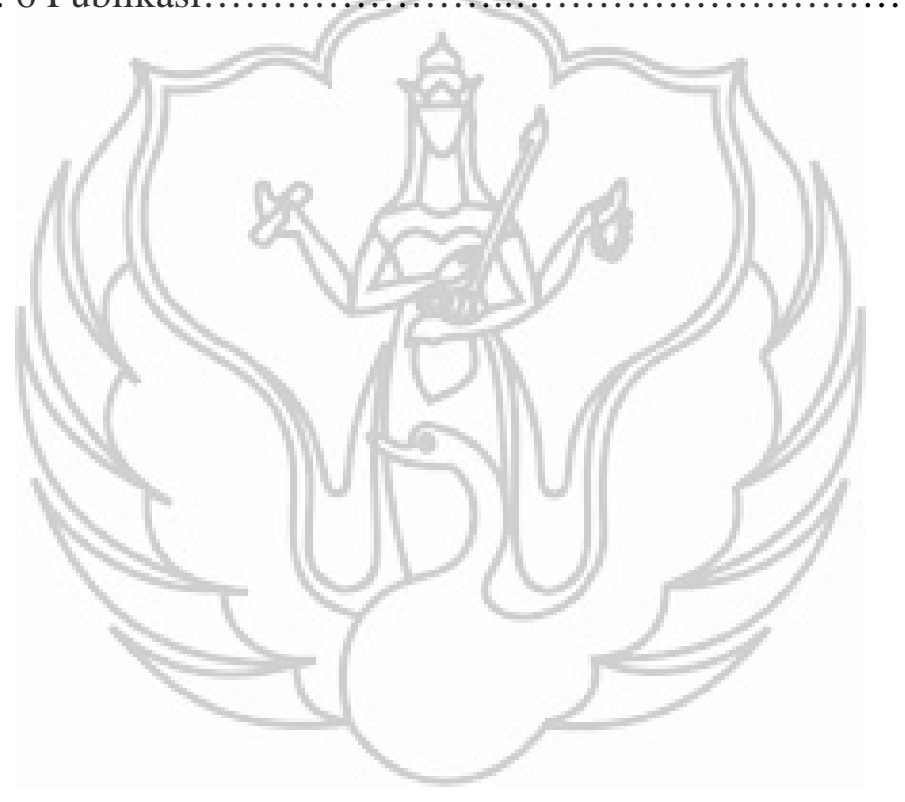




\section{ABSTRAK \\ Penciptaan Tokoh Gendut Dalam Naskah \\ Terdampar Karya Slawomir Mrozek \\ Terjemahan A. Kasim Ahmad \\ Oleh: Tiara Arianggi}

Dalam suatu kehidupan, manusia memiliki pola fikir dan juga eksistensinya masing-masing di luar pengaruh manusia lainnya.Membicarakan mengenai menusia secara personal yang memiliki pola fikir, bahwasanya suatu eksis, eksistensi dan eksistensialis dalam setiap individu manusianya, tidak bisa diterima selalu oleh manusia lain, karena terkadang suatu eksistensialis melahirkan peristiwa absurd setelahnya. Absurd artinya tidak rasional dan tidak dapat diterima oleh akal dan fikiran manusia, tetapi sesuatu yang absurd tidak bisa dijelaskan secara global, karena absurd akan diakui oleh orang-orang yang tidak melakoninya dan juga terjadi jika mengingkari norma-norma yang ada.

Dalam naskah Terdampar, upaya mempertahankan eksistensi dalam suatu realitas terjadi. Ketiga tokoh yang diberi nama Gendut, Sedang dan Kurus terjebak dalam suatu realitas di dalamnya, yang menciptakan eksistensi dalam diri masingmasing lalu mempertahankan kebenaran dengan melahirkan suatu peristiwa absurd.

Aktor memiliki perangkat yaitu tubuhnya sendiri, maka disini bagaimana aktor dapat mengaplikasikan dalam peran dan berbagai peran untuk dapat menciptakan karakter yang sesuai dari tokoh yang pilih.Aktor adalah seorang manusia individu yang memiliki pola pikir serta eksistensi nya sendiri, maka disini bagaimana seorang aktor dapat membenturkan eksistensinya terhadap karakter tokoh yang harus di mainkan di atas panggung.

Kata Kunci: Manusia, Aktor, Absurditas, Eksistensi

\section{UPT Perpustakaan ISI Yogyakarta}




\section{ABSTRACT \\ Creating Gendut in Terdampar Scrip work of Slawomir Mrozek Translation by. A. Kasim Ahmad \\ By: Tiara Arianggi}

In a life, people have the mindset and also the existence of each other beyond human influence. Talk about personal who have thought pattern, that one exists, and existentialist existence in every human individual, can not always be accepted by other human beings, because sometimes an existentialist bore absurd events thereafter. Absurd means irrational and unacceptable by reason and the human mind, but something that can not be explained absurd globally, because it is absurd to be recognized by people who do not practice it, and also occurs if denying the existing norms.

In the Terdampar sript, in an attempt to maintain the existence of reality occurs. The third character named Gendut, Sedang and Kurus trapped in a reality in it, which make existence within each and defend the truth by giving birth to an absurd incident.

Actors have a device the body, then here how actors can apply in roles and different roles in order to create the appropriate character from the character select. The actor is an individual human being who has the mindset and the existence of its own, so here how an actor can be banging their existence to the character to be played on stage.

Key words: Human, Actor, absurdity, Existence 


\section{BAB I}

\section{PENDAHULUAN}

\section{A. Latar Belakang}

Dalam pertunjukan teater, banyak komponen yang membuat pertunjukan tersebut bisa hadir. Salah satu komponen paling penting dalam sebuah pertunjukan teater adalah aktor. Tugas seorang aktor adalah memerankan tokoh. Kemudian ketika ingin membicarakan persoalan akting, bahwasanya akting berasal dari kata "to act" yang berarti beraksi. Akting dalam konteks ini adalah perpaduan antara atraksi fisikal (kebertubuhan), intlektual (analisis karakter dan naskah) dan spiritual (transformasi jiwa) (Saptaria, 2006 : 3). Untuk menjadi seorang aktor handal haruslah memiliki kesiapan yang lebih dari cukup. Mulai dari kesiapan tubuh, suara, hingga kesiapan jiwa.

Naskah lakon Terdampar karya Slawomir Mrozek terjemahan A. Kasim Ahmad memiliki judul asli Na Pelnym Morzu, yang di tulis pada tahun 1961 di Polandia. Naskah ini menceritakan tentang tiga orang yang terdampar di atas sebuah kapal di tengah lautan, dengan kondisi psikologi yang berbeda.

Masalah mulai muncul saat persediaan makanan habis. Ketiganya membentuk sebuah kampanye. Kampanye itu untuk mencalonkan siapa yang tidak dimakan. Dengan besar hati mereka harus dapat menyelesaikan permasalahan itu terus menerus agar tetap bertahan hidup.Dua orang yaitu Gendut dan Sedang membuat suatu kelompok untuk terus memojokkan si Kurus untuk

\section{UPT Perpustakaan ISI Yogyakarta}


dimakan. Akhirnya, setelah melewati proses berunding, mereka sepakat untuk memakan salah satu dari mereka, si Kuruslah yang mereka jadikan calon untuk dimakan. Sebenarnya si Sedang telah menemukan makanan dari dalam perahu mereka, tetapi si Gendut tetap menginginkan si Kurus untuk tetap dimakan. Dengan berat hati si Kurus jadi pasrah karena benar - benar tak ada lagi yang dapat diharapkan.

Gambaran seorang tokoh yang bernama Gendut, bahwasanya dia adalah seorang endormorphicyang mempunyai fisik gendut. Mempunyai kecerdasan dan kelicikan untuk bisa membaca situasi bahkan saat - saat genting atau susah sama sekali, diplomatis, diktaktor. Tokoh Sedang mesomorphic, yaitu orang yang selalu aktif, energetik, mencari prestasi dan agresif, licik dan juga provokator. Fisik yang ideal, tidak kurus dan tidak gendut. Tokoh Kurus ectomorpihic yaitu orang yang sensitif, intelektual dan suka menyendiri. Dia merupakan manusia yang sering memberontak, orang yang selalu tertindas dan akhirnya terkalahkan dengan keadaan.

Dengan naskah lakon Terdampar karya Slawomir Mrozek yang bercerita tentang situasi absurd dijelaskan pada sikap para tokoh yang sama-sama terdampar di laut dalam keadaan kondisi psikologi yang berbeda, yang melahirkan ketidakmungkinan sebagai sindiran keadaan politik saat itu. Pada tahun 1961, Eropa sedang diguncang krisis kemanusiaan dalam permasalahan kehidupan sosial politik. Ada tema sosial dalam konflik massa atau masyarakat dengan individu. Individu yang menginginkan kebebasan dalam memperjuangkan

\section{UPT Perpustakaan ISI Yogyakarta}


eksistensi dalam melawan kebekuan, kecurigaan, formalisme dan dogmatisme sosial, kadang - kadang konflik itu menunjukkan pada arah adanya ketegangan antara pandangan hidup modern yang individualities dengan pandangan hidup tradisional yang masih kolektif (Sumarjo, 2004:368).

Lakon Terdampar ini merupakan suatu bentuk cerita yang unik untuk dijadikan pertunjukkan drama, karena konflik yang terjadi didalamnya tidak serta merta menunjukkan hal yang biasa. Cerita lakon yang ada didalamnya mengkemas suatu konflik besar negara yang di analogikan secara sederhana melalui perebutan tentang makan - memakan.

Pertunjukkan lakon Terdampar akan dikemas dalam bentuk drama musikal. Drama musikal adalah suatu bentuk kesenian yang dikolaborasikan antara musik, laku, gerak dan tari yang menggambarkan suatu cerita yang dikemas dengan tata koreografi dan musik yang menarik sehingga terbentuklah sebuah drama musik.. Selain berdasarkan pada bentuk, drama musikal memiliki batasan tingkat kerumitan yang cukup tinggi bagi seorang aktor. Harus memadukan antara nada pada peristiwa, juga emosi saat itu. Pemilihan naskah Terdampar untuk sumber penciptaan dikarenakan dalam naskah tersebut memungkinkan seorang aktor berekspresi dengan singing, dancing, acting, untuk mencapai nilai kesempurnaan.

\section{UPT Perpustakaan ISI Yogyakarta}




\section{B. Rumusan Penciptaan}

Berdasarkan permasalahan yang telah dipaparkan di atas, maka rumusan masalah penciptaan adalah sebagai berikut.

1. Bagaimana karakter tokoh Gendut dalam naskah Terdampar?

2. Bagaimana memerankan tokoh Gendut dalam pertunjukkan Terdampar?

\section{Tujuan Penciptaan}

Tujuan penciptaan keaktoran dalam tokoh Gendut dalam naskah Terdampar adalah sebagai berikut:

1. Untuk memahami karakter Gendut dalam naskah Terdampar

2. Untuk memerankan Tokoh Gendut dalam pertunjukkan teater dalam naskah Terdampar.

\section{Tinjauan Karya}

Naskah Terdampar ini bukanlah sesuatu yang baru, tentu saja sebelumnya sudah ada yang mementaskan. Terdampar pernah dijadikan sebagai bahan tugas akhir penyutradaraan A.M. Setyaji dan tata artistik Elizabeth Christin pada tahun 2007 di Auditorium Institut Seni Indonesia Yogyakarta Fakultas Seni Pertunjukkan Jurusan Teater. A.M Setyaji dan Elizabeth Christin hal yang lebih ditekankan adalah pada capaian artistik dan penyutradaraan. Pertunjukan Terdampar pada tahun 2007 lalu itu dibawakan dengan bentuk artistik sett berupa

\section{UPT Perpustakaan ISI Yogyakarta}


Pirates of Carribean tanpa menggunakan nyanyian seperti di pertunjukan opera atau pun drama musikal.

Dalam pementasan Tugas Akhir kali ini yang berjudul Terdampar karya Slawomir Mrozek akan di pentaskan dalam kemasan drama musikal, dimana perbagian peristiwa menghadirkan nyayian serta dialog. Pementasan akan dibawa pada tahun 1800an, tidak lupa juga dengan set dekor yang sangat jauh berbeda dengan pementasan sebelumnya, yaitu dengan menggunakan koral. Dalam naskah Terdampar tidak hanya semata - mata melahirkan peristiwa seseorang yang sedang kelaparan karena kehabisan bahan makanan, tetapi mengenai eksistensi manusia yang akhirnya mencipkan peristiwa absurd di dalamnya. Menghadirkan tokoh Gendut sebagai seorang pemimpin, tokoh Sedang sebagai bawahan dan tokoh kurus sebagai buruh. Terdampar dalam arti lain, kehilangan arah dan lautan menggambarkan pemikiran manusia. Peristiwa satir yang tercipta, merupakan suatu bentuk perwakilan pada masa Polandia sedang diguncang atau mengalami krisis kemanusian dalam permasalahan kehidupan politik.

\section{E. Landasan Teori}

Naskah Terdampar karya Slawomir Mrozek yang diterjemahkan oleh A. Kasim Ahmad yang akan difokuskan dalam penciptaan tokoh Gendut dengan menggunakan rujukan dari teori Bretolt Brech, karena di dalam memainkan tokoh Gendut terdapat akting, pidato, dan beberapa akting yang sengaja dilakukan oleh aktor serta sengaja ditunjukkan pada penonton sebagai efek alienasi. Bagi Brecht

\section{UPT Perpustakaan ISI Yogyakarta}


tujuan utama pertunjukan teater bukanlah menumbuhkan katarsis, tetapi menyadarkan orang-orang yang terlibat di dalamnya bahwa kondisi sosial dapat diubah. Kondisi sosial bukan sesuatu yang terberi, tetapi merupakan konstruk buatan manusia. Oleh karena itu dapat diubah. Untuk mencapai tujuannya, Brecht menghindari empati dengan cara menciptakan apa yang disebut $V$-Effect. V- Effect adalah bentuk pengasingan agar penonton tidak terlibat secara emosial dengan pertunjukan.

Bertolt Brecht memiliki banyak konsep untuk menghadirkan V-Effect, yaitu V-effet dalam struktur cerita, syair dan nyanyian, sisipan cerita, dan spiel im spiel. Dalam pertunjukan Terdampar tidak semua konsep dalam teori Brecht tersebut dipakai. Konsep yang akan digunakan adalah alienasi berupa patahan peristiwa di beberapa adegan dan nyayian dengan tidak menghilangkan makna. Juga adanya teori Brech menjadi dan tidak menjadi, maka aktor memakai cara stilisasi dalam berakting memerankan tokoh.

Efek alienasi dalam teater Brechtian dimaksudkan untuk membangkitkan sikap intelektual kritis penonton. Teater Absurd berbicara kepada lapis yang lebih dalam dari pikiran manusia. Ia mengaktifkan kekuatan-kekuatan psikologis, melepaskan dan membebaskan ketakutan-ketakutan tersembunyi maupun agresi-agresi yang ditindas, dan lebih dari itu semua, dengan menghadapkan penontonnya pada suatu gambaran disintegrasi, maka teater Brechtian menggerakkan suatu proses aktif dari berbagai kekuatan terpadu dalam pikiran setiap individu penonton (Mukhid, 2008: 314).

Seperti yang diungkapan Ludwik Flaszen dalam Shomit Mitter tentang alienasi, sebagai berikut.

\section{UPT Perpustakaan ISI Yogyakarta}


Alienasi berisikan titik balik objek yang seseorang harus menyadarinya dari sesuatu yang biasa, akrab, diperoleh langsung, kepada sesuatu yang khusus, menggetarkan dan tak terduga. Sebelum keakraban berubah menjadi kesadaran, akrab harus dihilangkan dari kemapanannya, kita harus berhenti memperkirakan bahwa objek yang ditanyakan tidak memerlukan kejelasan (Mitter, 2002:59).

Beberapa rujukan dalam pertunjukan yang diambil dari Bertolt Brech sebagai efek alienasi adalah sebagai berikut.

1. Saat berpidato yang di sampaikan dengan nyayian, yaitu adegan saat berkampanye. Sedang bernyayi sembari memperkenalkan dirinya yang pintar memasak daging, dengan meyakinkan bahwa dirinya tidak pantas untuk dimakan.

2. Setalah Gendut berseteru dengan Kurus, lalu Gendut mencoba berfikir untuk mengeluarkan berstrategi demi mengalahkan Kurus. Adegan ini dimulai dengan nyayian yang membahas mengenai anak yatim. Kalimat nyayian yang di tuturkan, tidak ada dalam naskah, tetapi mengambil sebagian dari lagu Andrew Sister pada tahun 1943 di Inggris, dengan kalimat yang disambungkan dengan dialog selanjutnya dalam naskah. Berikut sebagian lirik yang dinyayikan.

I lost my mother, I lost my father

And now im losing you too

I shoot my mother, I shoot my father

And now im going to shoot...

One and only shoot, on you (Youtube, 1943: Andrews Sisters)

\section{UPT Perpustakaan ISI Yogyakarta}


3. Datangnya seorang tukang pos secara tiba-tiba dari dalam lautan menuju ke darat untuk menyampaikan telegram kepada kurus, setelah tugasnya selesai, Tukang Pos tersebut kembali tenggelam.

4. Datangnya seorang Buttlermenggunakan rakit dari tengah laut mencari Yang Mulia, yaitu tertuju pada si Gendut. Gendut tidak menyukai kehadiran Buttler yang sedari kecil mengasuhnya, maka Buttler tersebut di usir dari hadapanya dan tenggelam.

5. Peristiwa kepergian Buttler, membuat percecokan kembali antara Gendut dan Kurus. Gendut dan Sedang sudah semakin terlihat persekongkolan diantaranya untuk memojokkan kurus. Kurus mulai tidak terima atas perlakuan yang menututnya tidak adil. Maka sebagai patahan peristiwa, Kurus keluar dari panggung dengan amarah yang memuncak, Sedang mengejar Kurus dan Gendut menyelamatkan/pertunjukkan dengan bernyayi juga menari. Para crew yang ada di dalam pohon serta karang, ikut keluar dan menari. Tidak/lama Kurus dan Sedang kembali ke panggung, Gendut pun berhenti bernyayi. Kurus keluar dari tokohnya dan menyatakan bahwa dia tidak menyukai peran yang di mainkan. Setelah perdebatan panjang, mulai lah masuk kedalam dialog dan peristiwa sebelumnya. Yang terjadi adalah adanya perubahan emosi, baik emosi penonton dan aktor.

6. Saat adegan terakhir, Kurus menyerahkan dirinya dengan ikhlas untuk dimakan. Saat sebelum menyerahkan diri, Kurus meminta ijin untuk

\section{UPT Perpustakaan ISI Yogyakarta}


berpidato. Pidato yang di sampaikan dengan begitu dalam lalu dituturkan dengan nyayian hingga tutup tirai panggung.

Selain itu, teori Brech yang dipakai adalah stilisasi dengan menjadi dan tidak menjadi. Stilisasi dilakukan karena naskah ini tidak bisa dibawakan dengan realis, terlihat dari segi peristiwa yang ada dalam adegan-adegan yang tertera serta dialog yang dituturkan. Menjadi dan tidak menjadi adalah bagaimana aktor dapat keluar dari tokohnya, dan bisa mengkritisi tokoh yang akan dimainkan. Serta adanya capaian untuk dapat melampaui empati yang tidak lagi hanya merasakan dari dalam diri tokoh tersebut dengan menggunakan efek stilisai dari karakter tokoh yang dimainkan.

Melalui pendekatan keaktoran dengan menggunakan rujukan dari teori Bertold Brech dirasa mampu untuk mewujudkan tokoh/Gendut secara utuh. Walaupun dalam proses perjalanan/selama pelatihan kemungkinan akan mengalami penambahann teori lainnya untuk menutupi kekurangan dari teori Brech dalam metode ataupun teori keaktoran itu sendiri.

\section{F. Metode Memerankan Tokoh}

Dalam proses penciptaan karakter tokoh Gendut dalam naskah Terdampar ini, ada tiga aspek penting yaitu akting, gerak, dan nyanyian. Ketiga hal ini tentu tidak akan terlepas dari apa yang telah tersurat maupun tersirat dalam suatu pertunjukkan opera. Kecendrungan seorang aktor terjebak mempersamakan karakteristik-karakteristik psikologi emosinya sendiri dengan karakteristik-

\section{UPT Perpustakaan ISI Yogyakarta}


karakteristik psikologi tokoh. Untuk menampilkan karakter tokoh adapun proses yang perlu dilakukan untuk memperkaya tubuh aktor dengan cara sebagai berikut:

1. Analisis Naskah

Seorang aktor yang akan mementaskan suatu pertunjukkan, harus mengetahui terlebih dahulu isian dalam naskah tersebut. Tahap ini merupakan tahap awal sebagai acuan untuk memahami tokoh yang akan dimainkan, juga selain itu menentukan motivasi gerak dan dialog yang di tuturkan.

\section{Menentukan Lawan Main}

Tahap ini merupakan tahap dimana seorang aktor mencari lawan main yang pas, atas tokoh yang harus dimaikan. Dengan berdiskusi dengan sutradara dan teman - teman yang terlibat sebagai tokoh utama di dalam naskah Terdampar. Pentingnya mencari tokoh untuk lawan main karena akan berpengaruh terhadap tokoh penciptaan, terutama dalam bentuk fisik, yaitu Gendut, Sedang dan Kurus. Fisik yang disesuaikan dengan nama tokoh masing - masing di dalam naskah Terdampar.

\section{Latihan Tangga Nada}

Pertunjukkan drama musikal adalah suatu pertunjukkan kolaborasi antara musik, laku, gerak dan tari yang menggambarkan suatu cerita. Dalam pertunjukkan drama musikal, lebih kepada dinyayikan daripada dituturkan. Pertunjukkan ini biasanya dinyayikan dengan suara nada yang tinggi. Maka berlatih olah nada dan vokal adalah salah satu hal wajib, untuk mencapai

\section{UPT Perpustakaan ISI Yogyakarta}


tingkat dimana aktor dapat mengenali utuh suara nada dalam tekanan emosi yang berubah dalam waktu yang tidak menentu. Selain itu untuk menciptakan tokoh dan karakter Gendut, juga memenuhi suatu syarat pertunjukkan. Penguasaan suara dalam seni acting pada dasarnya adalah penguasaan diri secara utuh, karena kedudukan suara dalam hal ini hanyalah merupakan salah satu alat ekspresi dan totalitas diri kita sebagai seorang pemain (aktor) (Arifin, 2005:77).

Pelaksanaan yang akan dilalui dengan cara vocalizing atau bisa dikatakan pemanasan sebelum bernyayi, lalu berlatih tangga nada untuk mengenal nada dan yang terakhir melatih arpeggio atau memainkan tangga nada secara tidak berurutan. Hal ini tentunya akan/melatih dan membatu agar nada - nada yang akan dinyayikan tidak fals. Juga melatih tarikan suara seperti mengenal tone dan capain mengambil suara tertinggi. Selanjutnya menciptakan nada - nada dalam beberpa dialog dalam naskah Terdampar.

\section{Pencarian Refrensi Film atau Dokumentasi Pertunjukkan}

Salah satu cara efektif untuk dapat memenuhi atau mendapatkan gambaran secara jelas mengenai peristiwa yang ada kaitanya dalam naskah yang akan di maikan adalah menacari refrensi - refrensi yang sudah ada, baik menonton film ataupun dokumenatsi pementasan panggung. Tujuannya adalah untuk memperkaya dan menjadi bahan acuan kita untuk menciptakan suatu bentuk atau peran yang akan dimaikan.

\section{UPT Perpustakaan ISI Yogyakarta}




\section{Observasi Tokoh}

Aktivitas yang dilakukan terhadap suatu proses, dengan maksud merasakan dan kemudian memahami. Seorang aktor haruslah memahami capaian yang harus di tempuh agar dapat menciptakan tokoh yang akan di mainkan secara utuh. Maka obeservasi untuk menciptakannya, bagaimana seorang aktor haruslah memiliki strategi atau statement agar dapat memahami situasi, perasaan, atau emosi apa yang sedang terjadi. Imajinasi tidak cukup untuk dijadikan bahan acuan dalam proses penciptaan. Observasi bagian dari hal wajib yang harus dilakukan, agar dapat menciptakan logika dan empiris secara nyata.

\section{Penciptaan Karakter Tokoh}

Penciptaan ini dapat dilakukan setelah melakukan observasi, dengan bekal yang sudah ada dan objektif secara empiris, emosional, maka karakter akan tidak terlalu sulit untuk di ciptakaan.

Observasi biasanya dilakukan untuk menemukan bukti konkrit suatu peran. Sehingga ketika mencipta suatu karakter, seorang aktor akan mempunyai pegangan yang kuat. Observasi bisa dilakukan dimana saja, tergantung pada peran yang akan dimainkan.

7. Melatih Gesture

Pemahaman atas gesture atau bahasa tubuh haruslah didahului dengan membaca buku-buku tentang kepribadian dan bahasa tubuh itu sendiri, kemudian dari situ kita dapat memahami bahwa setiap

\section{UPT Perpustakaan ISI Yogyakarta}


gesturememiliki arti tertentu selebihnya tinggal melatih setiap persendian gerak dengan jangkauan semaksimal mungkin setiap detilnya.

\section{G. Sistematika Penulisan}

Sistematika penulisan di dalam skripsi ini sebagai berikut :

Bab I Pendahuluan berisi penulisan skripsi yang membahas tentang perencanaan rancangan tokoh Gendut dalam naskah Terdampar. Dalam bab I persoalan yang akan di bahas adalah latar belakang, rumusan penciptaan, tujuan penciptaan, tinjauan karya, landasan teori, metode memerankan tokoh, sistematika penulisan.

Bab II Analisis Karakter dan membahas secara keseluruhan lakon cerita dalam naskah Terdampar karya Slawomir Mrozek terjemahan A. Kasim Ahmad. Pembahasan di mulai dari Pengarang dan Pemikirannya, Analisis Struktur (Tema,

Plot atau Alur, Penokohan, Latar Cerita, Latar Waktu, Latar Sosial, Latar Kejadian), Analisis Tekstur (Dialog, Spktakel, Suasana). Dari ananlisis karakter tokoh maka akan tercipta eksplorasi dan rancangan pemeranan yang di gunakan untuk lebih mendukung proses terciptanya tokoh Gendut dalam naskah Terdampar.

Bab III Proses Pemeranan membahas terhadap jawaban - jawaban yang di pertanyakan dalam rumusan ide. Mengulas maksud dan tujuan yang dilakukan selama proses perancangan peran tokoh Gendut dalam naskah Terdampar. Beberapa hal yang akan dibahas dalam proses pemeranan dalam bab III adalah konsep pemeranan, proses training, pertunjukkan utuh, proses penciptaan pemeranan dalam pementasan.

\section{UPT Perpustakaan ISI Yogyakarta}


BAB IV Kesimpulan dan Saran yang membahas tentang kesimpulan dan saran dari diri aktor sendiri, penonton sebagai saksi terjadinya peristiwa di atas panggung, ataupun dari pihak - pihak yang mendukung proses kreatif dalam pementasan Terdampar yaitu dosen pembimbing, penguji ahli, juga para dosen yang berkompeten di bidangnya untuk di jadikan proses pembelajaran demi meningkatkan mutu dan kualitas sebagai insan kreatif. Bab ini juga sekaligus rekapan dari pembahasan bab sebelumnya menjadi satu bagian yang utuh.

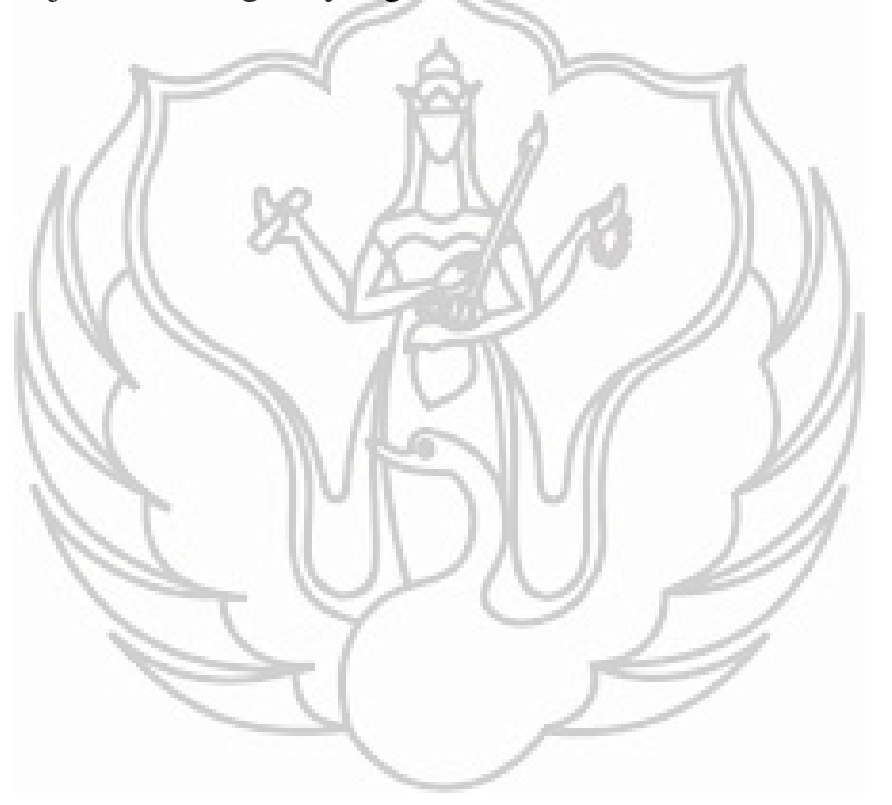

\section{UPT Perpustakaan ISI Yogyakarta}

